\title{
New Halogenated Phenylbacteriochlorins and Their Efficiency in Singlet-Oxygen Sensitization
}

\author{
Marta Pineiro, A. M. d'A. Rocha Gonsalves, Mariette M. Pereira, \\ Sebastião J. Formosinho, ${ }^{\dagger}$ and Luis G. Arnaut* \\ Departamento de Quimica, Universidade de Coimbra, Rua Larga 3049-Coimbra, Portugal and \\ Universidade Católica Portuguesa, P-3080 Figueira da Foz, Portugal
}

Received: October 3, 2001; In Final Form: January 14, 2002

\begin{abstract}
Halogenated phenylbacteriochlorins are synthesized with high yields in a two-step procedure. They have strong absorbances in the red and are very stable to air and light at room temperature. Flash photolysis measurements show that the triplet states of these bacteriochlorins have $30 \mu$ s lifetimes in deaerated toluene, that are quenched with diffusion-controlled rate constants by molecular oxygen. Time-resolved photoacoustic measurements, with nanosecond and nanocalorie resolution, show that these bacteriochlorins sensitize the formation of singlet oxygen with nearly unity quantum yield. However, singlet-oxygen phosphorescence measurements indicate that physical quenching occurs before the singlet-oxygen molecules diffuse into solution, and nearly half of the sensitized singlet states are lost.
\end{abstract}

\section{Introduction}

Stable molecular species with long-lived triplet states formed by the absorption of red or near-infrared light, play an important role in photochemistry. They may find application as catalysts in photooxidation reactions, ${ }^{1}$ photoinsecticidal agents, ${ }^{2}$ and drugs for photodynamic therapy. ${ }^{3-5}$ Furthermore, they may contribute to our understanding of triplet-triplet energy transfer processes and their relation to electron transfer. ${ }^{6-9}$ Such molecular species act as sensitizers, which absorb light and transfer its energy to molecular oxygen. This leads to the formation of singlet-oxygen, which may oxidize nearby species. When this is the mechanism, the efficiency of the sensitizer depends on its absortivity in the red or near-infrared, and of its efficiency in generating singletoxygen. These two aspects must be combined in a molecule that can be made in large quantities with high purity.

In our earlier work, ${ }^{10,11}$ we showed that the substitution of $\mathrm{H}$ atoms in the 2 and 6 positions of 5,10,15,20-tetrakisarylporphyrins (TPP) and 5,10,15,20-tetrakisarylchlorins by $\mathrm{F}$ and $\mathrm{Cl}$ atoms, significantly increases their singlet-oxygen quantum yield $\left(\Phi_{\Delta}\right)$. This is a consequence of the increase in the intersystem crossing rate due to the presence of heavy atoms. On the other hand, the reduction of one pyrrol ring increases the absorption coefficient of the lowest energy band, $\epsilon_{660} \approx 2 \times 10^{3} \mathrm{M}^{-1} \mathrm{~cm}^{-1}$ for the porphyrins and $\epsilon_{660} \approx 3 \times 10^{4} \mathrm{M}^{-1} \mathrm{~cm}^{-1}$ for the chlorins. We showed that these porphyrins and chlorins are sufficiently stable to be efficient sensitizers for photooxidation reactions. ${ }^{1}$ We expect that the reduction of another pyrrole ring, leading to the analogous bacteriochlorins, would increase even further the absorption in the red. In this work we describe an efficient synthetic method for 5,10,15,20-tetrakishalogenophenylbacte-

* To whom correspondence should be addressed. Universidade de Coimbra, E-mail lgarnaut@ci.uc.pt.

$\dagger$ Universidade de Coimbra and Universidade Católica Portuguesa.

List of abbreviations: TPP- 5,10,15,20-tetrakisphenylporphyrin; TDFPB - 5,10,15,20-tetrakis(2,6-difluorophenyl)bacteriochlorin; ToCPB5,10,15,20-tetrakis(2-chlorophenyl)bacteriochlorin; TDCPB - 5,10,15,20tetrakis(2,6-dichlorophenyl)bacteriochlorin; PAC- Time-resolved photoacoustic calorimetry; NiNC- Ni(II)-2,11,20,29-tetra-tert-butyl-2,3-naphthalocyanine. riochlorins (Chart 1) and show that these new molecules have intense absorptions ca. $745 \mathrm{~nm}$, while they are stable species with long-lived triplet states.

\section{Experimental Section}

Instrumentation. ${ }^{1} \mathrm{H}$ NMR spectra were recorded on a 300 $\mathrm{MHz}$ Bruker-AMX spectrometer. Mass spectra were obtained on a VG autospec and elemental analysis on EA1108-CHNS-0 Fisons Instruments. Absorption spectra were recorded with a Shimadzu UV-2100 spectrophotometer. Fluorescence and phosphorescence spectra were measured with a Spex Fluorolog 3 spectrophotometer, with correction for the wavelength dependence of the detection system (RCA C31034 photomultiplier and the 1934D3 module for phosphorimetry). Flash photolysis employed an Applied Photophysics LKS.60 laser flash photolysis spectrometer, with a Spectra-Physics Quanta-Ray GCR$130 \mathrm{Nd}$ :YAG laser and a Hewlett-Packard Infinium Oscilloscope $(1 \mathrm{MS} / \mathrm{s})$; the samples were irradiated with the third harmonic of the laser $(355 \mathrm{~nm})$, the monitoring white light was produced by a $150 \mathrm{~W}$ pulsed Xe lamp and the detection of the transient spectra in the 300-900 nm range was made with Hamamatsu 1P28 and R928 photomultipliers. Time-resolved photoacoustic calorimetry (PAC) measurements were performed in a homemade apparatus following the front-face irradiation design described by Arnaut et al. ${ }^{12}$ and discussed in detail elsewhere..$^{10,11,13,14}$ Singlet-oxygen phosphorescence decays were measured at the Norwegian University of Science and Technology (Trondheim) using a third harmonic of a Nd:YAG laser to pump a optical parametric oscillator (BM Industries) tuned to $517 \mathrm{~nm}$, and operating with a laser intensity of $10 \mathrm{~mJ} /$ pulse and frequency of $10 \mathrm{~Hz}$. The phosphorescence was measured with a Hamamatsu R5509 photomultiplier cooled to $-80{ }^{\circ} \mathrm{C}$, using a long-pass filter transmitting wavelengths longer than $700 \mathrm{~nm}$, followed by an interference filter with peak transmission of $52 \%$ centered at $1272.5 \mathrm{~nm}$.

Materials. All solvents and reagents (Aldrich) were purified by standard methods before use. Ni(II)-2,11,20,29-tetra-tertbutyl-2,3-naphthalocyanine (NiNC) was used as purchased from 
CHART 1: Bacteriochlorins, and Respective Abbreviations, Studied in This Paper
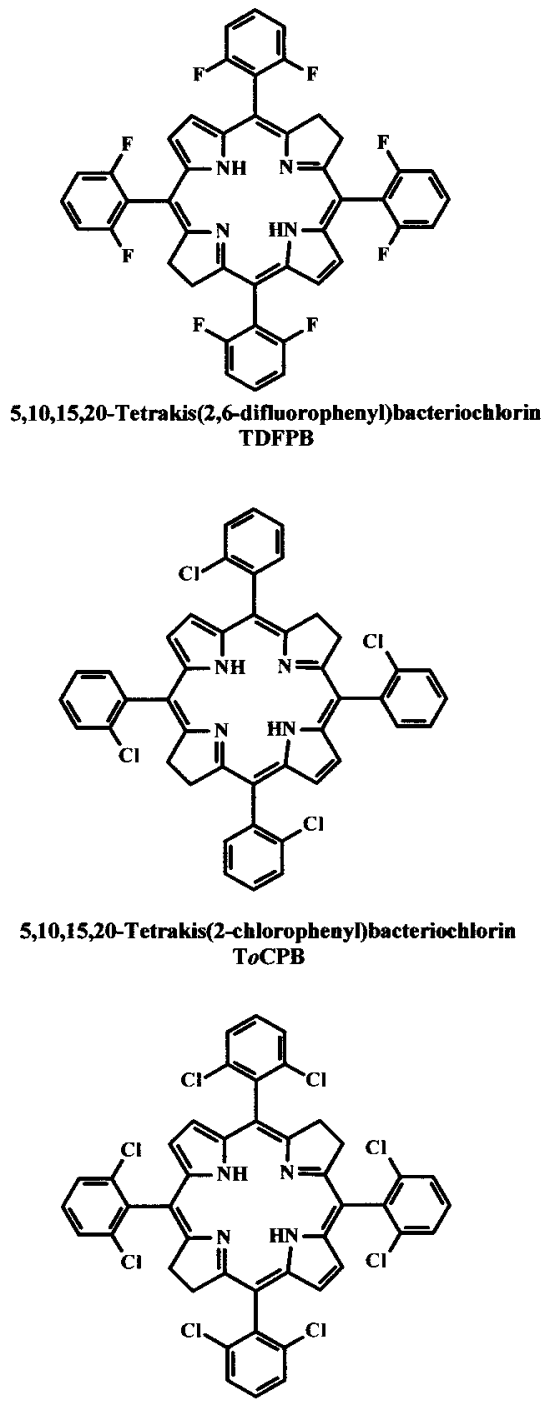

5,10,15,20-Tetrakis(2,6-dichlorophenyl)bacteriochlorin TDCPB

Aldrich. All the photophysical and photochemistry measurements were carried out in toluene.

Bacteriochlorin Synthesis. The halogenated porphyrins were synthesized according to the procedures described elsewhere. ${ }^{10,15}$ The yields of the isolated products were $11 \%$ for $5,10,15,20$ tetrakis(2,6-difluorophenyl)porphyrin, 3\% for 5,10,15,20-tetrakis(2-chlorophenyl)porphyrin, and 5\% for 5,10,15,20-tetrakis(2,6-dichlorophenyl)porphyrin. The bacteriochlorins were prepared from the corresponding porphyrins following two alternative procedures.

Procedure A. The porphyrin $(0.10 \mathrm{mmol})$ and $p$-toluenesulfonylhydrazine $(4.0 \mathrm{mmol}, 744 \mathrm{mg}$ ) were dissolved in 100 $\mathrm{mL}$ of $\mathrm{N}_{2}$-saturated xylene and the temperature raised to 140 ${ }^{\circ} \mathrm{C}$. The reaction was monitoring by UV-vis spectroscopy until the 744 or $747 \mathrm{~nm}$ absorption band (typical of bacteriochlorins) reached its highest value and then more $p$-toluenesulfonylhydrazine $(4.0 \mathrm{mmol}, 744 \mathrm{mg})$ was added. The reaction was stopped when the band at 744 or $747 \mathrm{~nm}$ reached its maximum. After cooling, xylene was removed in a vacuum and the product dissolved in chloroform, washed with water $(20 \mathrm{~mL} \times 10)$, dried with $\mathrm{Na}_{2} \mathrm{SO}_{4}$ and was crystallized from chloroform.

After crystallization, NMR- ${ }^{1} \mathrm{H}$ analysis showed that the bacteriochlorin is contaminated with only a small amount of the corresponding chlorin. The yields from $\mathrm{RMN}-{ }^{1} \mathrm{H}$ analysis are $88 \%, 76 \%$, and $90 \%$ for TDFPB, ToCPB, and TDCPB, respectively. The corresponding chlorin can be removed by silica preparative thin-layer chromatography using toluene as eluent for TDFPB and ToCPB and toluene/chloroform (60/40) for TDCPB. Isolated yields and characterization after recrystallization from chloroform are presented below.

Procedure B. The porphyrin $(0.10 \mathrm{mmol}), p$-toluenesulfonylhydrazine ( $4.0 \mathrm{mmol}, 744 \mathrm{mg}$ ), and $\mathrm{CO}_{3} \mathrm{~K}_{2}$ ( $4.0 \mathrm{mmol}, 552$ $\mathrm{mg}$ ) were dissolved in $100 \mathrm{~mL}$ of $\mathrm{N}_{2}$-saturated $\alpha$-picoline and the temperature raised to $120{ }^{\circ} \mathrm{C}$. The reaction was monitored by UV-vis spectroscopy as described above, and more $p$ toluenesulfonylhydrazine ( $4.0 \mathrm{mmol}, 744 \mathrm{mg}$ ), as well as $\mathrm{CO}_{3} K_{2}$ (4.0 mmol, $552 \mathrm{mg}$ ), were added. After cooling, $100 \mathrm{~mL}$ of water were added; the precipitate was washed with methanol and recrystallized from chloroform. The yields from $\mathrm{RMN}-{ }^{1} \mathrm{H}$ analysis are 95\%, 88\%, and 95\% for TDFPB, ToCPB, and TDCPB, respectively. The purification was made as described for procedure A. Yields after recrystallization are presented.

5,10,15,20-Tetrakis(2,6-difluorophenyl)bacteriochlorin (TDFPB). Yield (procedure A): 52\%; Yield (procedure B): $71 \%$; ${ }^{1} \mathrm{H}$ NMR $\left(300 \mathrm{MHz}, \mathrm{CDCl}_{3}\right): \delta=8.07(\mathrm{~d}, 4 \mathrm{H}, J=1.3 \mathrm{~Hz})$, $7.68-7.58(\mathrm{~m}, 4 \mathrm{H}), 7.4-7.24(\mathrm{~m}, 8 \mathrm{H}), 4.08(\mathrm{~s}, 8 \mathrm{H}),-1.31(\mathrm{~s}$, $2 \mathrm{H}$ ); $\mathrm{MS}$ (FAB): $m / z=762$ (molecular ion); $\mathrm{C}_{44} \mathrm{H}_{26} \mathrm{~N}_{4} \mathrm{~F}_{8}$ : calcd C 69.29, H 3.41, N 7.35; found C 69.24, H 3.42, N 7.31.

$\mathbf{5 , 1 0 , 1 5 , 2 0 - T e t r a k i s ( 2 - c h l o r o p h e n y l ) b a c t e r i o c h l o r i n ~}$ (ToCPB). Yield (procedure A): 51\%; Yield (procedure B): $63 \%{ }^{1} \mathrm{H}$ NMR $\left(300 \mathrm{MHz}, \mathrm{CDCl}_{3}\right): \delta=7.86(\mathrm{sl}, 4 \mathrm{H}), 7.83-$ $7.67(\mathrm{~m}, 8 \mathrm{H}) ; 7.61-7.53(\mathrm{~m}, 8 \mathrm{H}), 3.91(\mathrm{sl}, 8 \mathrm{H}),-1.32(\mathrm{~s}, 2 \mathrm{H})$; MS (FAB): $m / z=756$ (molecular ion); $\mathrm{C}_{44} \mathrm{H}_{30} \mathrm{~N}_{4} \mathrm{Cl}_{4}$ : calcd C 69.84, H 3.97, N 7.41; found C 69.79, H 3.90, N 7.46.

5,10,15,20-Tetrakis(2,6-dichlorophenyl)bacteriochlorin (TDCPB). Yield (procedure A): 55\%; Yield (procedure B): $57 \%$; ${ }^{1} \mathrm{H}$ NMR $\left(300 \mathrm{MHz}, \mathrm{CDCl}_{3}\right): \delta=7.89(\mathrm{~d}, 4 \mathrm{H}, J=1,9 \mathrm{~Hz})$, 7.75-7.65 (m, 8H), 7.56-7.51 (m, 4H), 3.94 (s, 8H), -1.27 (s, $2 \mathrm{H}$ ); MS (FAB): $m / z=894$ (molecular ion); $\mathrm{C}_{44} \mathrm{H}_{26} \mathrm{~N}_{4} \mathrm{Cl}_{8}$ : C 59.06, H 2.91, N 6.26; found C 59.12, H 2.85, N 6.21.

Bacteriochlorin Luminescence. Fluorescence quantum yields were measured according to published procedures. ${ }^{10,11,16}$ All the solutions were carefully deoxygenated with $\mathrm{N}_{2}$, previously saturated in toluene. The fluorescence spectra were recorded for all bacteriochlorins with excitation light at $\lambda_{\max }$ of the $\mathrm{Q}_{x}$ $(0,0)$ and $\mathrm{Q}_{y}(0,0)$ bands. TPP and TDFPB were used as reference for the calculation of fluorescence quantum yields with excitation at the $\mathrm{Q}_{x}(0,0)$ and $\mathrm{Q}_{y}(0,0)$ bands, respectively. Fluorescence excitation spectra were obtained for all bacteriochlorins at the fluorescence band and agreed well with the corresponding absorption spectra. Attempts to measure phosphorescence in toluene at liquid nitrogen temperature did not reveal any band below $900 \mathrm{~nm}$.

Flash Photolysis. Air and $\mathrm{N}_{2}$-saturated solutions with absorbances between 0.2 and 0.4 at the Soret band, were irradiated with the third harmonic of the Nd:YAG laser $(355 \mathrm{~nm}, 50 \mathrm{~mJ}$, $8 \mathrm{~ns}$ fwhm). Triplet-triplet absorption spectra were obtained for all the bacteriochlorins. Their decays at 310, 400, and 790 $\mathrm{nm}$ were followed in the presence and absence of air, and fitted to one exponential.

Photoacoustic Calorimetry. We followed our protocol for PAC measurements. ${ }^{10,11,13}$ Bacteriochlorins were irradiated at the maximum of the $\mathrm{Q}_{x}(0,0)$ and $\mathrm{Q}_{y}(0,0)$ bands with a $\mathrm{N}_{2^{-}}$ pumped dye laser and using respectively trans- $\beta$-carotene and $\mathrm{Ni}(\mathrm{II})$-2,11,20,29-tetra-tert-butyl-2,3-naphthalocyanine as calorimetric reference. 


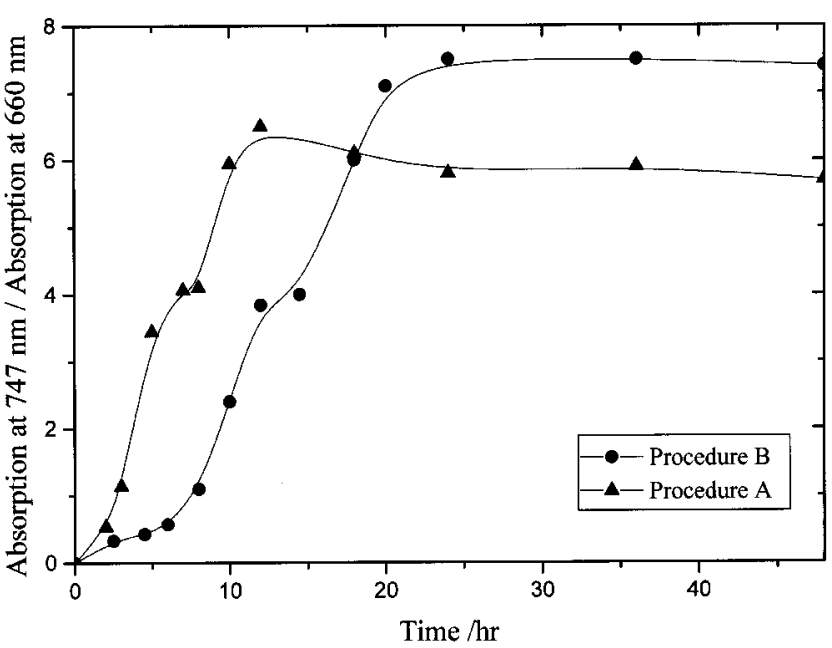

Figure 1. Growth of TDCPB absorbance using procedure $\mathrm{A}$ and procedure $\mathrm{B}$ conditions as measured by the ratio between the absorption at 747 and $660 \mathrm{~nm}$.

TABLE 1: Yields from RMN-1 H Analysis, after Crystallization of Reaction Product, after $24 \mathrm{~h}$ of Reaction Time

\begin{tabular}{ccccc}
\hline & porphyrin/diimide & $\begin{array}{c}\text { TDFPB } \\
\%\end{array}$ & $\begin{array}{c}\text { ToCPB } \\
\%\end{array}$ & $\begin{array}{c}\text { TDCPB } \\
\%\end{array}$ \\
\hline $\begin{array}{c}\text { procedure A } \\
\text { (xylene) }\end{array}$ & $(1 / 40) \times 2$ & 88 & 76 & 90 \\
procedure B & $(1 / 40)$ & 61 & 64 & 67 \\
$\quad(\alpha$-picoline $)$ & $(1 / 80)$ & 85 & 87 & 84 \\
& $(1 / 40) \times 2$ & 95 & 88 & 95
\end{tabular}

Singlet-Oxygen Phosphorescence. The absorbance of airsaturated solutions of $\mathrm{C}_{60}$ in benzene and bacteriochlorins or TPP in toluene was adjusted to 0.300 at $517 \mathrm{~nm}$. Each solution was irradiated with 257 laser shots in a standard $1 \mathrm{~cm}$ quartz cell and the corresponding singlet-oxygen emissions were averaged. The emission of the $\mathrm{C}_{60}$ solution was taken as reference for the calculation of singlet-oxygen phosphorescence quantum yields. The approximate time response of this setup is $0.1 \mu \mathrm{s}$.

\section{Results}

Synthesis. The 5,10,15,20-tetrakishalogenobacteriochlorins were synthesized using two different conditions for the diimide generation. In the procedure called $\mathrm{A}$, the porphyrin and $p$-toluenesulfonylhydrazine is refluxed in xylene and the diimide is generated by thermal cleavage (ca. $140{ }^{\circ} \mathrm{C}$ ). ${ }^{17}$ In procedure $\mathrm{B}$, the porphyrin, $p$-toluenesulfonylhydrazine and $\mathrm{CO}_{3} \mathrm{~K}_{2}$ are refluxed in $\alpha$-picoline, and the diimide is generated by reaction with base. ${ }^{17}$ Both procedures give high yields of bacteriochlorin. The yields, from $\mathrm{RMN}-{ }^{1} \mathrm{H}$ analysis, for the same reaction time and different additions of precursors, are presented in Table 1. In both cases the reaction product is a mixture of a bacteriochlorin and a chlorin, without appreciable quantities of degradation products.

$\mathrm{UV}$ - vis was used to follow the reaction taking aliquots (30 $\mu \mathrm{L} / 3 \mathrm{~mL}$ ) from the reaction mixture and the ratio between de absorbance at $745 \mathrm{~nm}$ and the absorbance at $655 \mathrm{~nm}$ was registered. Figure 1 shows the growth of TDCPB in both procedures, which is representative of all the compounds studied.

The stability of the three bacteriochlorins (solutions $7 \times 10^{-4}$ M) to air, light, and temperature, in xylene and $\alpha$-picoline, was studied by UV-vis spectroscopy following de evolution of longwavelength absorbance bands of the bacteriochlorins $\left(\lambda_{\max }=745\right.$ $\mathrm{nm})$ and chlorins $\left(\lambda_{\max }=655 \mathrm{~nm}\right)$ with the time, Figure 2.

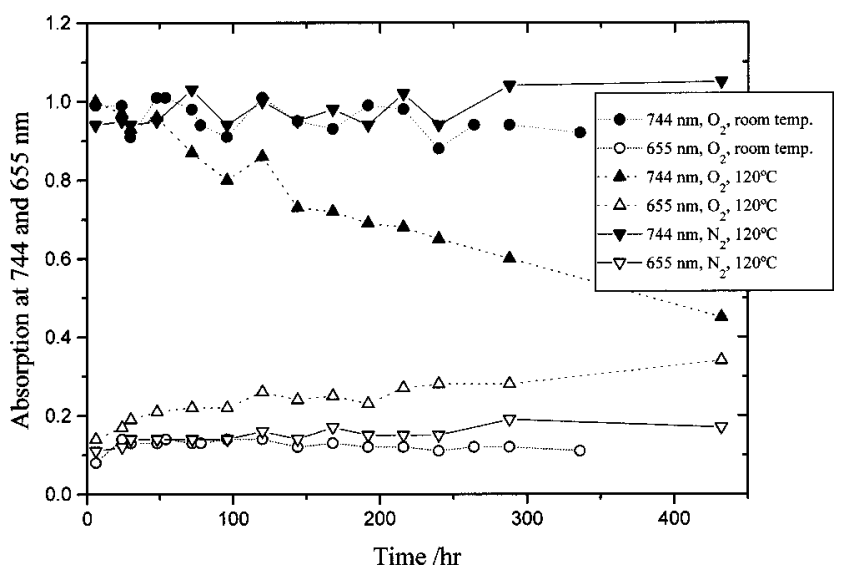

Figure 2. Stability of TDFPB, after crystallization from the reaction mixture (procedure $\mathrm{B}$ ), at room temperature in aerated solutions and at $120{ }^{\circ} \mathrm{C}$ in aerated and $\mathrm{N}_{2}$-saturated solutions. The solutions were diluted by a factor of 100 before measuring the absorbance of the $\mathrm{Q}_{x}(0,0)$ bands of TDFPB $(744 \mathrm{~nm})$ and of the respective chlorin $(655 \mathrm{~nm})$.

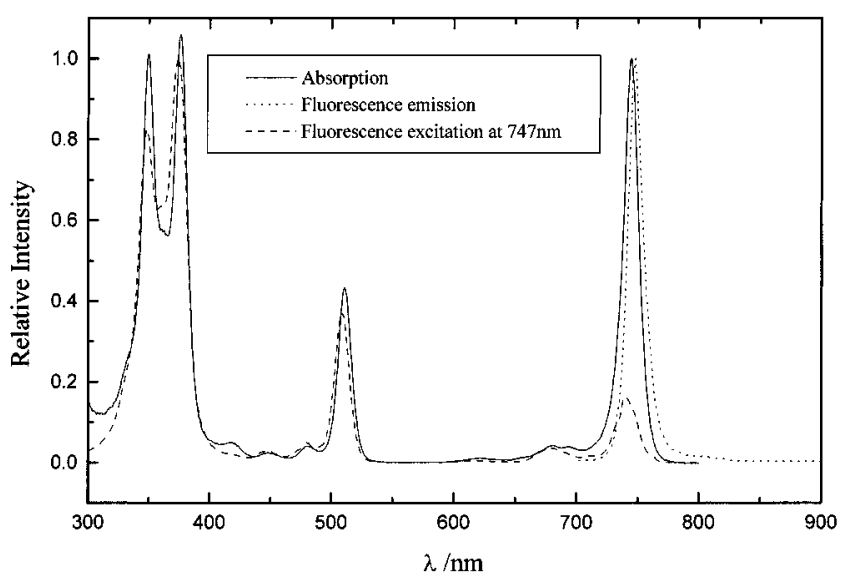

Figure 3. Absorption, fluorescence spectrum (excitation at $744 \mathrm{~nm}$ ) and fluorescence excitation spectrum at $748 \mathrm{~nm}$ of TDCPB. Absorption and fluorescence spectra are normalized at $747 \mathrm{~nm}$.

The bacteriochlorins were purified on silica gel thin-layer chromatography, using toluene as eluent and solvent. A mixture of toluene/chloroform (60/40) proved to be more convenient for the separation of TDCPB, due to its poor solubility in pure toluene. During the concentration process, after chromatography, the formation of up to $8 \%$ chlorin is unavoidable.

Photophysics and Photochemistry. The influence of $8 \%$ chlorin in some of our samples was carefully assessed in these studies. We always irradiated the samples at wavelengths where the bacteriochlorin absorbs more than $99.5 \%$ of the incident light. We can rule out all the interference of the chlorins in our photophysical measurements based on the following facts: 1 . A detailed study of the chlorins ${ }^{11}$ showed that they do not undergo any photochemistry in our reaction conditions; 2 . PAC measurements with irradiation at $747 \mathrm{~nm}$ (where the chlorin does not absorb light) and $510 \mathrm{~nm}$ (the most adverse conditions, where the chlorin absorbs $0.5 \%$ of the light) gave the same results; 3 . A specially prepared bacteriochlorin sample with less than $1 \%$ chlorin (Figure 3, where the band at $410 \mathrm{~nm}$ is the chlorin and has the same absorption coefficient as the bacteriochlorin at $744 \mathrm{~nm}$ ), gave the same results as the other samples. The problem of chlorin contamination is usually ignored. However, in large-scale applications of bacteriochlorins it will be unavoidable. 
TABLE 2: Absorption and Fluorescence Data of Bacteriochlorins

\begin{tabular}{|c|c|c|c|c|c|c|c|c|c|}
\hline & \multicolumn{6}{|c|}{ Absorption } & \multicolumn{3}{|c|}{ Fluorescence } \\
\hline & \multicolumn{6}{|c|}{$\lambda_{\max }(\mathrm{nm}) \epsilon\left(\mathrm{M}-{ }^{1} \mathrm{~cm}-{ }^{1}\right)$} & \multirow{2}{*}{$\frac{\lambda(\mathrm{nm})}{\mathrm{Q}(0,0)}$} & \multirow[b]{2}{*}{$\mathrm{E}_{\mathrm{S}} \mathrm{kcal} \mathrm{mol-1}$} & \multirow[b]{2}{*}{$\Phi_{\mathrm{F}}$} \\
\hline & $\mathrm{B}_{\mathrm{y}}(0,0)$ & $\mathrm{N}_{\mathrm{x}}(0,0)$ & $\mathrm{Q}_{\mathrm{x}}(1,0)$ & $\mathrm{Q}_{\mathrm{x}}(0,0)$ & $\mathrm{Q}_{\mathrm{y}}(1,0)$ & $\mathrm{Q}_{\mathrm{y}}(0,0)$ & & & \\
\hline TDFPB & $\begin{array}{l}349 \\
1.62 \times 10^{5}\end{array}$ & $\begin{array}{l}376 \\
1.67 \times 10^{5}\end{array}$ & $\begin{array}{l}481 \\
5.7 \times 10^{3}\end{array}$ & $\begin{array}{l}510 \\
7.6 \times 10^{4}\end{array}$ & $\begin{array}{l}681 \\
\quad 6.0 \times 10^{3}\end{array}$ & $\begin{array}{r}744 \\
1.4 \times 10^{5}\end{array}$ & 745 & $38.4 \pm 0.8$ & $0.068 \pm 0.07$ \\
\hline $\mathrm{T} o \mathrm{CPB}$ & $\begin{array}{l}353 \\
1.48 \times 10^{5}\end{array}$ & $\begin{array}{l}378 \\
\quad 1.71 \times 10^{5}\end{array}$ & $\begin{array}{l}484 \\
\quad 3.7 \times 10^{3}\end{array}$ & $\begin{array}{l}516 \\
8.0 \times 10^{5}\end{array}$ & $\begin{array}{l}685 \\
\quad 3.7 \times 10^{3}\end{array}$ & $\begin{array}{r}744 \\
1.4 \times 10^{5}\end{array}$ & 745 & $38.5 \pm 0.7$ & $0.048 \pm 0.003$ \\
\hline TDCPB & $\begin{array}{l}353 \\
\quad 1.32 \times 10^{5}\end{array}$ & $\begin{array}{l}379 \\
1.44 \times 10^{5}\end{array}$ & $\begin{array}{l}482 \\
2.4 \times 10^{3}\end{array}$ & $\begin{array}{l}516 \\
\quad 7.4 \times 10^{4}\end{array}$ & $\begin{array}{l}682 \\
2.5 \times 10^{3}\end{array}$ & ${ }^{747} 1.26 \times 10^{5}$ & 748 & $38.3 \pm 0.9$ & $0.012 \pm 0.002$ \\
\hline
\end{tabular}

TABLE 3: Triplet Lifetimes and Quantum Yields Measurements by Flash Photolysis, Photoacoustic Calorimetry and Singlet-Oxygen Phosphorescence

\begin{tabular}{|c|c|c|c|c|c|c|}
\hline & \multicolumn{2}{|c|}{ flash photolysis } & \multicolumn{2}{|c|}{$\Phi_{\Delta}{ }^{\mathrm{PAC}}$} & \multicolumn{2}{|c|}{ singlet-oxygen phosphorescence } \\
\hline & $\tau_{\mathrm{T}}\left(\mathrm{N}_{2}\right) \mu \mathrm{s}$ & $\tau_{\mathrm{T}}\left(\mathrm{O}_{2}\right) \mathrm{ns}$ & $k_{\mathrm{q}} \times 10-9\left(\mathrm{M}^{-1} \mathrm{~s}^{-1}\right)$ & $(\lambda=745$ or $747 \mathrm{~nm})$ & $\Phi_{\Delta}^{\mathrm{L}}$ & $\tau\left(\mathrm{O}_{2}\left({ }^{1} \Delta_{\mathrm{g}}\right)\right) \mu \mathrm{s}$ \\
\hline TDFPB & $33 \pm 7$ & $216 \pm 5$ & $2.6 \pm 0.2$ & $0.78 \pm 0.08$ & 0.48 & 33 \\
\hline ТoCPB & $44 \pm 4$ & $265 \pm 10$ & $2.0 \pm 0.3$ & $0.95 \pm 0.08$ & 0.59 & 34 \\
\hline TDCPB & $32 \pm 3$ & $254 \pm 11$ & $2.1 \pm 0.1$ & $1.06 \pm 0.09$ & 0.60 & 33 \\
\hline
\end{tabular}

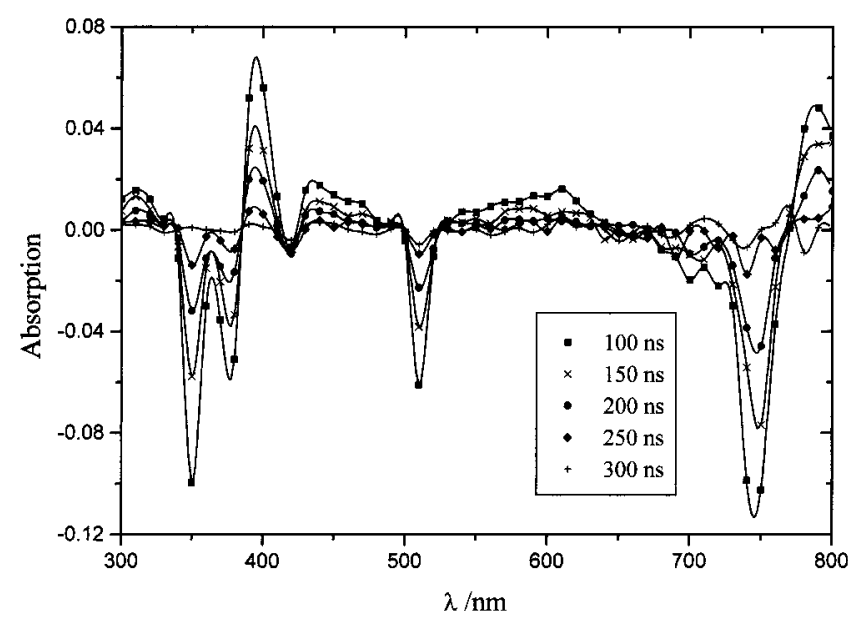

Figure 4. Triplet-triplet absorption spectrum of TDFPB in toluene.

All the photophysical measurements were carried out in toluene, using solutions with concentrations in the $10^{-5}-10^{-7}$ $M$ range where the Beer-Lambert law was always obeyed, and no evidence for aggregation was found. The absorption, fluorescence excitation and fluorescence emission spectra of TDFPB, representative of the three bacteriochlorins, are shown in Figure 3. The relevant absorption and fluorescence data are summarized in Table 2. We found no evidence for phosphorescence at $77 \mathrm{~K}$ below $900 \mathrm{~nm}$. The Stokes shifts are very small, and the spectroscopic energies of the first singlet state are nearly identical to the relaxed energies. The fluorescence quantum yields were measured with irradiation at the maximum of the $\mathrm{Q}_{x}(0,0)$ and $\mathrm{Q}_{y}(0,0)$ bands. In the irradiation of the $\mathrm{Q}_{x}(0,0)$ band, 5,15,20,25-tetrakisphenylporphyrin (TPP) was used as reference, and in the irradiation of the $\mathrm{Q}_{y}(0,0)$ band, TDFPB was used as reference for the other two bacteriochlorins. The fluorescence emission spectra with irradiation of the $\mathrm{Q}_{x}(0,0)$ band show small bands at 658,657 , or $661 \mathrm{~nm}$ for TDFPB, ToCPB and TDCPB. We identified these bands as the first emission band of the respective chlorins ${ }^{11}$ using fluorescence excitation. The emission of the chlorins contributes with less than $6 \%$ to the total fluorescence quantum yield, and was taken into account in the determination of the fluorescence quantum yields of the bacteriochlorins.

Flash photolysis reveals three important triplet-triplet absorption bands, at 310,400 , and $790 \mathrm{~nm}$, for all the bacteriochlorins (Figure 4). The decays at these wavelengths give triplet lifetimes longer than $30 \mu$ s in deaerated solutions, which are

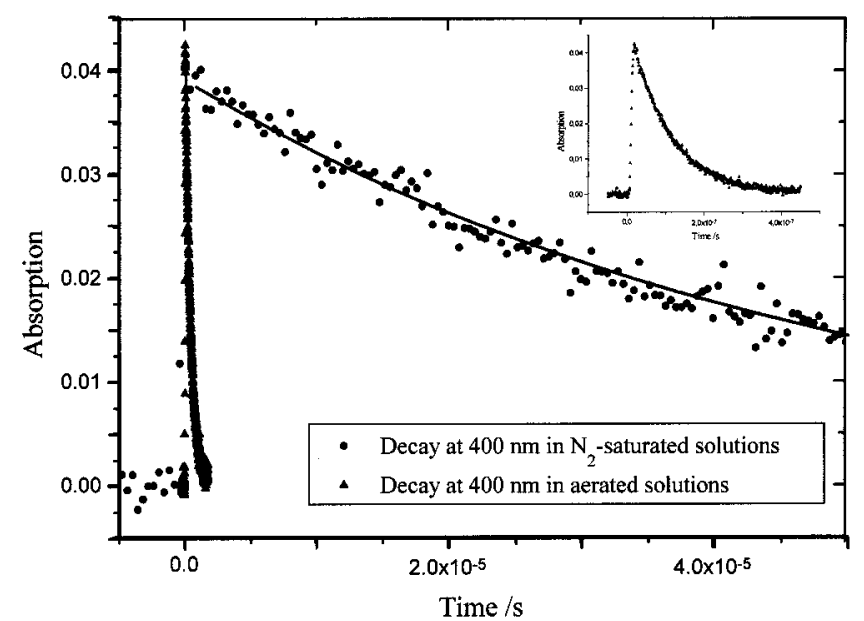

Figure 5. Analysis of the TDFPB triplet decays at $400 \mathrm{~nm}$ in the absence (circles) and presence of air (triangles). The bacteriochlorin was irradiated at $355 \mathrm{~nm}$. Each decay was fitted to a single exponential. The insert shows the decay in aerated toluene solutions in an expanded time window.

reduced to ca. $250 \mathrm{~ns}$ in aerated solutions. The oxygenquenching rate constant was calculated from the triplet lifetimes in aerated and deaerated toluene solutions at room temperature, and using $\left[\mathrm{O}_{2}\right]=1.81 \times 10^{-3} \mathrm{M}$ for air-saturated toluene solutions. The decays of TDFPB, representative of the other bacteriochlorins, at $400 \mathrm{~nm}$ in the presence and absence of air are presented in Figure 5. Table 3 presents the triplet lifetimes and the oxygen-quenching rates in toluene.

Time-resolved photoacoustic calorimetry (PAC) was carried out at the maximum of the $\mathrm{Q}_{x}(0,0)$ and $\mathrm{Q}_{y}(0,0)$ bands, ca. 515 and $745 \mathrm{~nm}$. At $515 \mathrm{~nm}$ we employed trans- $\beta$-carotene as the PAC reference. At $745 \mathrm{~nm}$ we had to use a new reference. $\mathrm{Ni}(\mathrm{II})$-2,11,20,29-tetra-tert-butyl-2,3-naphthalocyanine (NiNC) was selected for its absorption at this wavelength and its expected short lifetime. We verified if $\mathrm{NiNC}$ had the adequate properties to be used as a PAC reference prior to its use. Its fluorescence quantum yield is negligible. Its photoacoustic response is linear with the laser intensity and with the fraction of laser energy absorbed in the PAC cell. NiNC has the same PAC response as trans- $\beta$-carotene at $421 \mathrm{~nm}$. Thus, we believe that NiNC is a suitable PAC reference for studies at $\lambda>700$ nm. Figure 6 shows the photoacoustic waves of NiNC and TDFPB in the most extreme conditions employed in this study.

The interpretation of the photoacoustic waves was made with the kinetic scheme presented in Figure 7. We use a kinetic model 


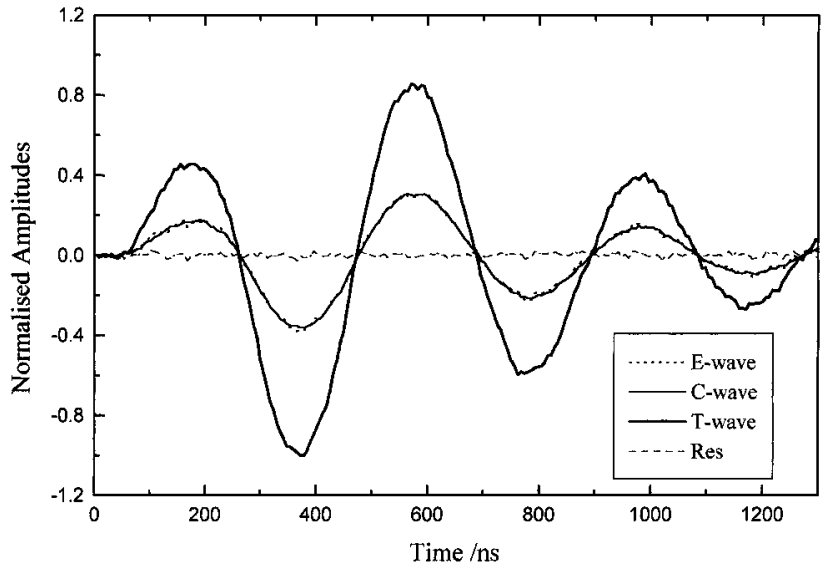

Figure 6. Normalized and background-corrected acoustic waves acquired from PAC experiments. T-wave: NiNC (calorimetric reference) in toluene with $\mathrm{A}_{744}=0.75$, E-wave: TDFPB in toluene $\mathrm{A}_{744}=$ 0.75 . The $\mathrm{C}$-wave was obtained convoluting the $\mathrm{T}$-wave with twosequential exponential decays of lifetimes $\tau_{1}=0.01 \mathrm{~ns}$ and $\tau_{2}=216$ $\mathrm{ns}$, the fractions of heat released calculated were: $\phi_{1}=0.3555$ and $\phi_{2}$ $=0.0460$. Res $=\mathrm{E}$-wave $-\mathrm{C}$-wave. Irradiation at $744 \mathrm{~nm}$ using a filter with $17 \%$ transmission. The optical path of the PAC cell is 0.22 $\mathrm{mm}$.

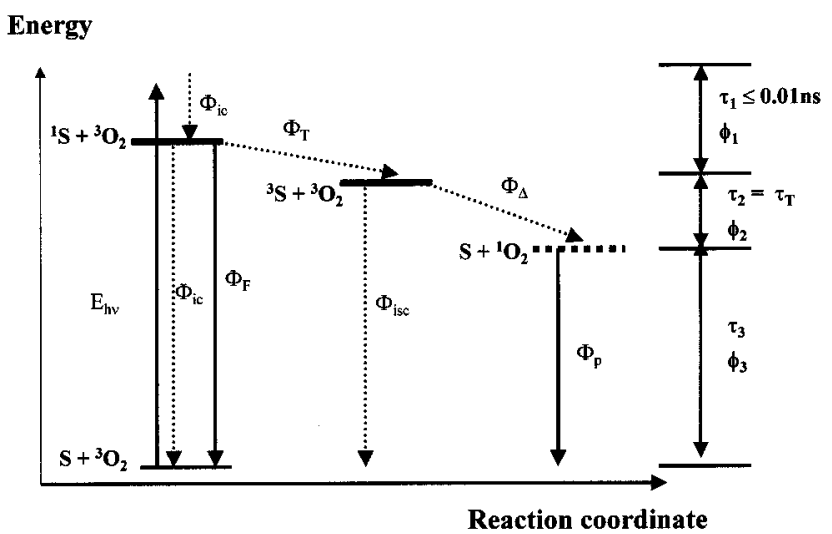

Figure 7. Kinetic scheme of the photoinduced process in the presence of molecular oxygen. Full lines: radiative process; dashed lines: radiationless process.

involving two sequential exponentials to deconvolute the photoacoustic waves. The formation of the triplet state of the sensitizer correspond to the first exponential and is described by the lifetime of its formation $\left(\tau_{1}\right)$ and by the fraction of energy released in that lifetime $\left(\phi_{1}\right)$. The lifetime $\tau_{1}$ is very short but its exact value is unknown. In the deconvolution process we set $\tau_{1}$ to $1,0.01$, or $0.001 \mathrm{~ns}$, and saw no difference in the value of $\phi_{1}$ obtained with the last two values. Thus, we set $\tau_{1}=0.01$ ns to obtain $\phi_{1}$, that is, the fraction of energy released in the formation of the triplet state. The agreement between calculated (C-wave) and experimental (E-wave) shown in Figure 6, is representative of the results obtained with our apparatus.

The product of the triplet quantum $\left(\Phi_{\mathrm{T}}\right)$ and energy $\left(E_{\mathrm{T}}\right)$ is given by

$$
\Phi_{\mathrm{T}} E_{\mathrm{T}}=\left(1-\phi_{1}\right) E_{\mathrm{h} v}-\Phi_{\mathrm{F}} E_{\mathrm{h} v \max }
$$

where $E_{\mathrm{h} v \max }$ is the energy at the maximum fluorescence intensity and $E_{\mathrm{h} v}=38.4 \mathrm{kcal} \mathrm{mol}^{-1}$ at $745 \mathrm{~nm}$.

In deoxygenated solutions, the triplet-state lifetime $\left(\tau_{\mathrm{T}}\right)$ is too long to be detectable with the $2.25 \mathrm{MHz}$ transducer employed in these PAC measurements, but flash photolysis experiments give $\tau_{\mathrm{T}} \approx 250 \mathrm{~ns}$ in aerated solutions. These decay times now

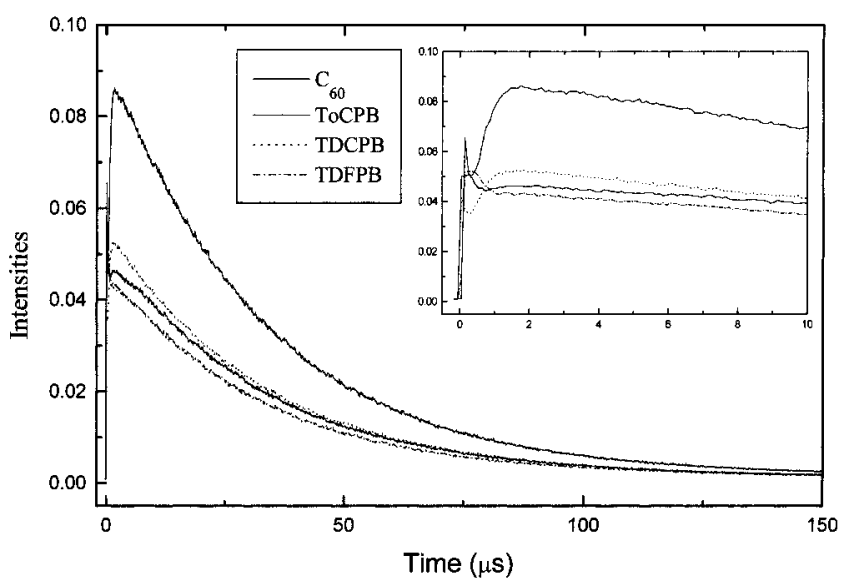

Figure 8. Singlet-oxygen phosphorescence decays observed following excitation of the sensitizers at $517 \mathrm{~nm}$. The inset shows the first microseconds of the decays.

fall in the time window of the $2.25 \mathrm{MHz}$ transducer. Thus, in aerated solutions, the lifetime of the second exponential obtained by deconvolution $\left(\tau_{2}\right)$, is associated with the triplet lifetime and with the fraction of energy released $\left(\phi_{2}\right)$ in its decay. Setting $\tau_{1}$ $=0.01 \mathrm{~ns}$ and $\tau_{2}=\tau_{\mathrm{T}}$, obtained by flash photolysis, the value of $\phi_{2}$ is given by the transfer of energy from the triplet state of the sensitizer to molecular oxygen. This methodology has been described in detail elsewhere. ${ }^{10,11,13,18,19}$ The singlet-oxygen quantum yields can now be estimated with

$$
\Phi_{\Delta} E_{\Delta}=\Phi_{\mathrm{T}} E_{\mathrm{T}}-\phi_{2} E_{\mathrm{h} v}
$$

knowing that the singlet-oxygen energy is $E_{\Delta}=22.5 \mathrm{kcal} \mathrm{mol}^{-1}$ and using the value of $\Phi_{\mathrm{T}} E_{\mathrm{T}}$ obtained with eq 1 .

The singlet-oxygen phosphorescence of aerated bacteriochlorin and TPP toluene solutions were measured relative to that of aerated benzene solutions containing $\mathrm{C}_{60}$ as the singlet-oxygen sensitizer. The phosphorescence quantum yields $\left(\Phi_{\Delta}{ }^{\mathrm{L}}\right)$ were determined from the relative phosphorescence decays, shown in Figure 8, using $\Phi_{\Delta}{ }^{\mathrm{L}}\left(\mathrm{C}_{60}\right)=1.0 .{ }^{14}$ Table 3 also includes the values of $\Phi_{\Delta}{ }^{\mathrm{L}}$ measured in this work. The phosphorescence traces are closely fit by monoexponential decays in the 7-120 $\mu$ s time range. The singlet-oxygen phosphorescence lifetimes $\tau\left(\mathrm{O}_{2}\left({ }^{1 \Delta} \mathrm{g}\right)\right)$ of the fresh solutions are presented in Table 3.

The absorption, fluorescence emission, triplet-triplet absorption spectra, and lifetime of the triplet state remained unchanged after photoacoustic experiments, indicating that the sensitizers did not decompose appreciably during the irradiation, independently of the presence of air and light.

\section{Discussion}

Synthesis. Our methodology allows the synthesis of a diversity of porphyrins on large amounts and these compounds allow the synthesis of bacteriochlorins in two steps. Reduced porphyrins could be made through formation of exocycles rings,${ }^{20-24}$ by saturation of double bonds with hydroxyl, ${ }^{25-34}$ cyanomethyl groups, ${ }^{5}$ or hydrogen. From these possibilities we choose the introduction of hydrogen because the structural modification is minimal and this is favorable for the study of the relationship between the photophysical and photochemical properties and the structure of these compounds.

All the methodologies employed for the introduction of hydrogen: photochemical reduction, ${ }^{35}$ catalytic hydrogenation, ${ }^{32}$ the reduction with sodium and isoamyl alcohol, ${ }^{36-38}$ and reduction with diimide ${ }^{32,39}$ are based upon the fact that at least two of the double bonds of the porphyrin structure are not 
SCHEME 1: Scheme of Diimide Generation, Porphyrin Reduction, and Diimide Decomposition Reactions
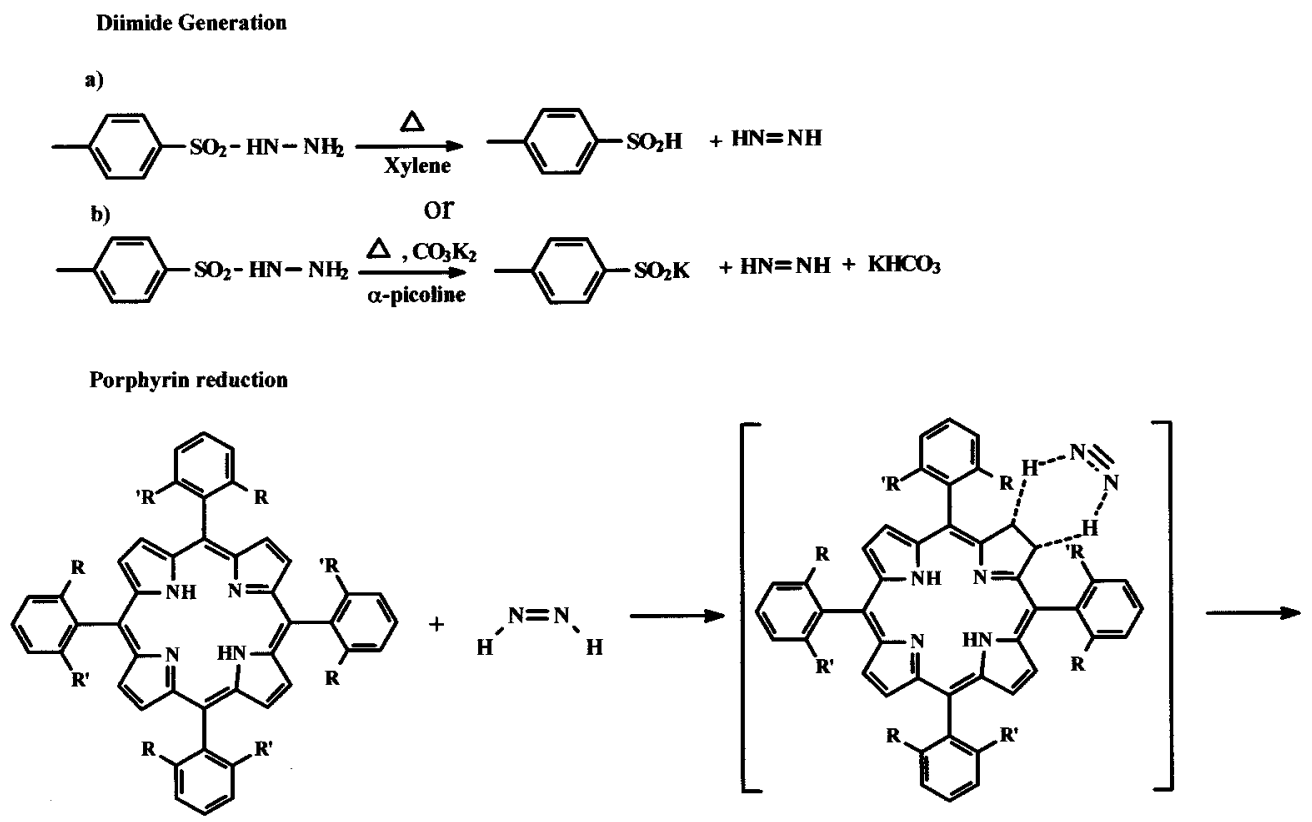

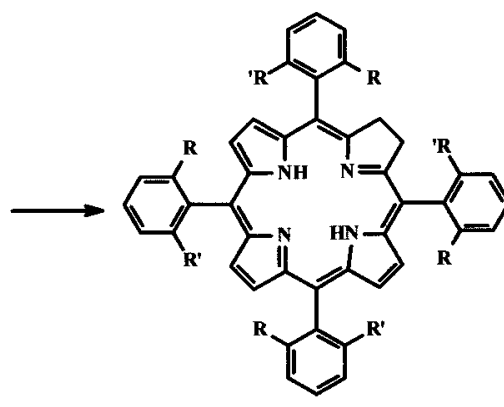

Diimide decomposition

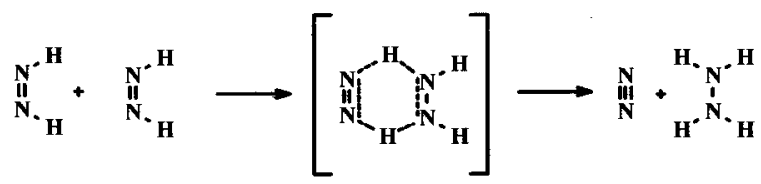

included in the 18 electron aromatic system. Thus, typical methods for reduction of isolated double bonds can be applied. Only the reduction with diimide was used for the treatment of $5,10,15,20$-tetrakisarylporphyrins and this is the methodology followed in this work for the synthesis of the new bacteriochlorins.

The synthesis was made using two different procedures, the generation of diimide from $p$-toluenesulfonylhydrazine through thermal cleavage and from $p$-toluenesulfonylhydrazine and $\mathrm{CO}_{3} \mathrm{~K}_{2}$. In both procedures the reduction of porphyrin follows the same mechanism and a large quantity of diimide precursors is necessary. The yields of bacteriochlorins are dependent on the amount of diimide precursors. When the addition to the reaction mixture is made in the ratio porphyrin/ $p$-toluenesulfonylhydrazine (1/40), (1/80) and in two batches of (1/40), the yields of bacteriochlorins obtained are ca. $65 \%, 85 \%$, and $90 \%$, respectively (Table 1 ). This suggest that a high percentage of diimide decomposed in the reaction conditions before the porphyrin reduction occurred, that is, the diimide decomposition ${ }^{17,40}$ is competitive with the reduction reaction (Scheme 1).

Figure 1 shows that after the first addition of diimide precursors there is an induction period, about $2 \mathrm{~h}$ in xylene and $6 \mathrm{~h}$ in $\alpha$-picoline. During this period, we observe the formation of the corresponding chlorin together with a small amount of bacteriochlorin. After this period, the two reactions have a very similar evolution, as can be observed by the similar slope of the curves: bacteriochlorin is formed and chlorin is consumed. Then, in both cases the bacteriochlorin formation rate is significantly reduced, probably due to the absence of diimide. With the addition of the same amount of diimide precursor, the rate of bacteriochlorin formation increases again. The overall yield is comparable in both procedures but the reaction time is nearly half time in procedure A (Figure 1).

At room temperature, in the absence and presence of oxygen, the reaction products are stable in xylene and $\alpha$-picoline, at least for 15 days. At temperatures higher than $120{ }^{\circ} \mathrm{C}$, the absence of oxygen is critical for the stability of these compounds. In the presence of oxygen the typical band of bacteriochlorins decreases gradually with the time. For example, after 432 h (18 days) only $45 \%$ of the TDFPB remains in solution and $42 \%$ of chlorin is formed (Figure 2). This is clearly indicative that the oxidation of bacteriochlorins at high temperatures in the presence of oxygen gives the chlorin.

Photophysics and Photochemistry. The reduction of $\Phi_{\mathrm{F}}$ in the series TDFPB, ToCPB, and TDCPB, is similar to that observed for porphyrins ${ }^{10}$ and chlorins,,${ }^{11}$ and consistent with the 
expected heavy-atom effect. If we assume that $\Phi_{\mathrm{T}} \approx 1-\Phi_{\mathrm{F}}$ for the deaerated halogenated bacteriochlorin solutions, as it is for the zinc halogenated porphyrins, eq 1 gives $\mathrm{E}_{\mathrm{T}}=24.7 \mathrm{kcal}$ $\mathrm{mol}^{-1}, 27.0 \mathrm{kcal} \mathrm{mol}^{-1}$, and $30.4 \mathrm{kcal} \mathrm{mol}^{-1}$ for TDFPB, $\mathrm{T} o \mathrm{CPB}$, and TDCPB, respectively. This corresponds to an energy gap of $9-14 \mathrm{kcal} \mathrm{mol}^{-1}$ between the $S_{1}$ and $T_{1}$ states of these bacteriochlorins, which is similar to the $S_{1}-T_{1}$ gap obtained for analogous porphyrins and metalloporphyrins. ${ }^{10}$ The phosphorescence of the bacteriochlorins should appear at 942$1160 \mathrm{~nm}$, and is beyond the sensitivity of our present photomultipliers. In the absence of phosphorescence we cannot use eq 1 to determine the exact $\Phi_{\mathrm{T}}$ values, but we can still employ the product $\Phi_{\mathrm{T}} E_{\mathrm{T}}$ obtained in these experiments to determine $\Phi_{\Delta}{ }^{\text {PAC }}$ using eq 2 and the values of $\phi_{2}$ determined in aerated solutions. The triplet lifetime employed in the PAC deconvolutions was measured by flash photolysis. We point out that the triplet-triplet absorption spectra of our bacteriochlorins have clear isosbestic points ca. 355, 385, 500, 520, and $770 \mathrm{~nm}$, suggesting that the triplet is quenched to the ground state. We also expected to see an isosbestic point at $420 \mathrm{~nm}$ but the presence of the chlorin bleaching obscures it. The values of $\Phi_{\Delta}{ }^{\text {PAC }}$ obtained at ca. $745 \mathrm{~nm}$ are shown in Table 3 and confirm the trends observed for $\Phi_{\mathrm{T}}$.

At this point, it is interesting to emphasize that the laser used in PAC has an energy ca. $50 \mu \mathrm{J} /$ pulse $(12 \mu \mathrm{cal})$ at $745 \mathrm{~nm}$, and that our standard working conditions require an absorbance of 0.01 in the PAC cell (considering the two light passes). Thus, in these experiments, the maximum energy absorbed was 0.12 $\mu \mathrm{cal} /$ pulse. Furthermore, our procedure calls for the use of filters to study the laser intensity dependence. The signals obtained for NiNC and TDFPB with a filter transmitting $17 \%$ of the 745 nm laser pulse are shown in Figure 5. The TDFPB wave was fitted with $\phi_{1}=0.33$, which means that it was generated by the release of 6.7 nanocalories in less than $10 \mathrm{~ns}$ (the time response of our PAC apparatus). These measurements are only possible given the remarkable sensitivity of our PAC cell.

The singlet-oxygen quantum yields $\left(\Phi_{\Delta}{ }^{\mathrm{PAC}}\right)$ measured by PAC for the bacteriochlorins are systematically larger than the corresponding singlet-oxygen phosphorescence quantum yields $\left(\Phi_{\Delta}{ }^{\mathrm{L}}\right)$. The two techniques measure different quantities and will only give the same results when the lifetime of the sample is identical to that of the reference. This is the case of singletoxygen sensitization by $\mathrm{C}_{60}$ in benzene and TPP in toluene, that give $\tau\left(\mathrm{O}_{2}\left({ }^{1 \Delta} \mathrm{g}\right)\right)=31.6$ and $31.2 \mu \mathrm{s}$, respectively, under identical sensitization conditions. We measured $\Phi_{\Delta}^{\mathrm{L}}=0.71$ using the sensitization by TPP, that is within the experimental error of $\Phi_{\Delta}{ }^{\text {PAC }}=0.69$ previously determined. ${ }^{10} \mathrm{We}$ expect to obtain $\Phi_{\Delta}{ }^{\mathrm{PAC}}>\Phi_{\Delta}^{\mathrm{L}}$ when the phosphorescence lifetime of the reference is longer than that of the sample, even if they are initially formed with the same quantum yield. The simplest explanation for the observation of $\Phi_{\Delta}{ }^{\mathrm{PAC}}>\Phi_{\Delta}{ }^{\mathrm{L}}$ is that there is a competition between singlet-oxygen phosphorescence and reaction with the bacteriochlorins. However, the lifetime of singlet-oxygen formed by sensitization by bacteriochlorins is only $5 \%$ lower than that of singlet-oxygen sensitized by $\mathrm{C}_{60}$. This is not enough to explain the $40 \%$ difference between $\Phi_{\Delta}{ }^{\text {PAC }}$ and $\Phi_{\Delta}{ }^{\mathrm{L}}$. Furthermore, the ratio of phosphoresce intensities at their maximum is only marginally higher than the quantum yields reported in Table 3 .

The long lifetime of singlet oxygen in the presence of bacteriochlorins is consistent with their long shelf life in aerated toluene solutions at room temperature. Furthermore, $\Phi_{\Delta}{ }^{\mathrm{L}}$ of bacteriochlorin-sensitized singlet oxygen decreases very little with time. The repetition of phosphorescence measurements after

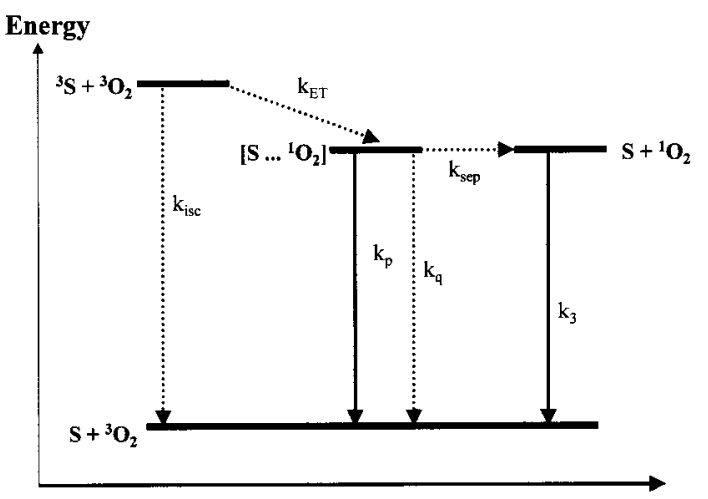

Reaction coordinate

Figure 9. Mechanism used to simulate the singlet-oxygen phosphorescence. It involves three-sequential exponential decays with rate constants $k_{1}=k_{\mathrm{ET}}\left[\mathrm{O}_{2}\right]+k_{\mathrm{isc}}, k_{2}=k_{\mathrm{sep}}+k_{\mathrm{q}}+k_{\mathrm{P}}$ and $k_{3}=k_{\mathrm{P}}$. The phosphorescence intensity is proportional to the quantity of $\left[\mathrm{S} \cdots{ }^{1} \mathrm{O}_{2}\right]$ and ${ }^{1} \mathrm{O}_{2}$ present at any given time.

a week of exposure of the solutions to ambient temperature and air, leads to $\Phi_{\Delta}{ }^{\mathrm{L}}=0.59,0.53$, and 0.45 for TDCPB, ТoCPB, and TDFPB, respectively.

It can be argued that the difference between $\Phi_{\Delta}{ }^{\mathrm{PAC}}$ and $\Phi_{\Delta}{ }^{\mathrm{L}}$ is related to the excitation wavelength, because the $\Phi_{\Delta}{ }^{\mathrm{L}}$ values were measured following irradiation at $517 \mathrm{~nm}$, where the chlorin impurity also absorbs. However, we also measured $\Phi_{\Delta}{ }^{\mathrm{PAC}}$ with irradiation at 510 or $516 \mathrm{~nm}$ using trans- $\beta$-carotene as a reference, and confirmed the values obtained at $745 \mathrm{~nm}$.

Reversible energy transfer between the triplet of the sensitizer and singlet oxygen could account for the low $\Phi_{\mathrm{P}}$. This mechanism was shown to be operative for phthalocyanines $\left(E_{\mathrm{T}}\right.$ $=22.8 \mathrm{kcal} / \mathrm{mol}),{ }^{41}$ but is expected to be inefficient for our bacteriochlorins $\left(E_{\mathrm{T}}=25-30 \mathrm{kcal} / \mathrm{mol}\right)$.

We have to return to the quenching of the singlet-oxygen phosphorescence by the bacteriochlorins, to find an explanation for the difference between $\Phi_{\Delta}{ }^{\mathrm{PAC}}$ and $\Phi_{\Delta}{ }^{\mathrm{L}}$. In the absence of changes in phosphorescence lifetimes or evidence for significant bacteriochlorin degradation, we can hypothesize that this quenching takes place shortly after the generation of singlet oxygen. The inset of Figure 8 shows the first 10 microseconds of the phosphorescence decays. It reveals that when $\mathrm{C}_{60}$ or TPP are used as sensitizers, there is a growth of the emission in the first 2 microseconds, whereas when TDFPB or ToCPB are the sensitizers, there is a fast decrease followed by the slow $(30-\mu \mathrm{s}$ lifetime) decrease. Approximately half of the phosphorescence intensity generated by TDFPB or ToCPB is lost in the first microsecond. This explains the difference between $\Phi_{\Delta}{ }^{\mathrm{PAC}}$ and $\Phi_{\Delta}{ }^{\mathrm{L}}$. The sensitization by TDCPB seems to fall in an intermediate case.

We can accommodate the available kinetic data with a simple modification of the reaction mechanism presented in Figure 7. The modified mechanism, the three-sequential exponential decays shown in Figure 9, involves the intermediacy of an emissive intermediate $\left[\mathrm{S} \cdots{ }^{1} \mathrm{O}_{2}\right]$. This intermediate has the properties of an exciplex and is related to that originally proposed by Stauff and Fuhr. ${ }^{42}$ Figure 10 shows that the basic features of the singlet-oxygen decays of TPP and TDFPB, calculated as the sum of the emission of $\left[S{ }^{\circ}{ }^{1} \mathrm{O}_{2}\right]$ and free ${ }^{1} \mathrm{O}_{2}$, can be explained by this modified mechanism. The calculation of the decays requires the knowledge of $\Phi_{\mathrm{T}}$, of the triplet lifetime in aerated solutions $\left(\tau_{\mathrm{T}}=1 / k_{1}\right)$, of the intermediate lifetime $\left(\tau_{\mathrm{I}}=1 / k_{2}\right)$, and the fraction of intermediates that proceed to free $\mathrm{O}_{2}\left({ }^{1} \Delta \mathrm{g}\right)\left(f_{\Delta}\right)$, and of the lifetime of free ${ }^{1} \mathrm{O}_{2}\left(\tau_{\Delta}=1 / k_{3}\right)$. The initial concentration of the triplet state is the product of a 

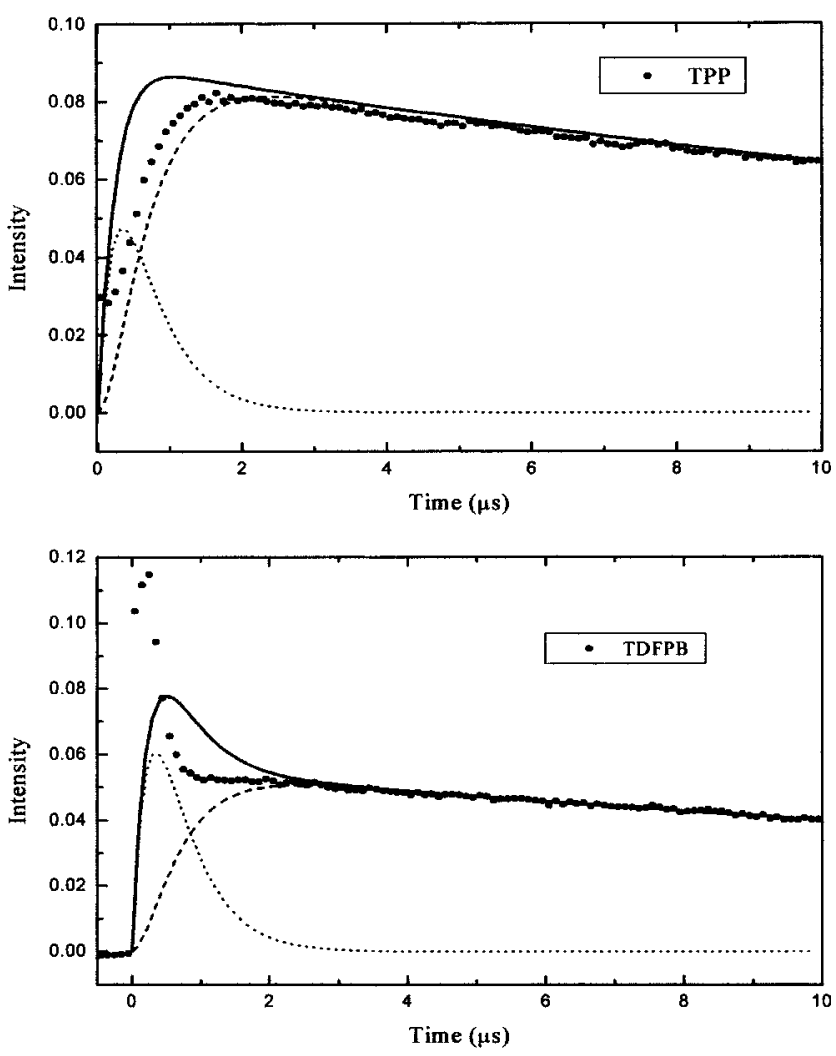

Figure 10. Simulation of the first 10 microseconds of the singletoxygen phosphorescence decays sensitized by TPP or by TDFPB, using the reaction mechanism of Figure 9. The points represent the experimental data. The emission from $\left[\mathrm{S} \cdots{ }^{1} \mathrm{O}_{2}\right]$ is shown as a dotted line and that of free ${ }^{1} \mathrm{O}_{2}$ is shown as a dashed line. The full line is the sum of the dotted and dashed lines. These simulations employed $k_{2}=2 \times$ $10^{6} \mathrm{~s}^{-1}$, but similar patters are observed with $k_{2}$ in the $10^{6} \mathrm{~s}^{-1}$ range. The other parameters used in the simulations are taken from the experimental information available for these systems.

scaling constant by the triplet quantum yield, $\Phi_{\mathrm{T}}(\mathrm{TPP})=0.73^{10}$ and $\Phi_{\mathrm{T}}(\mathrm{TDFPB})=0.93$. The pseudo-first-order rate constant for the quenching of the triplet states is taken from flash photolysis, $k_{1}=k_{\mathrm{ET}}\left[\mathrm{O}_{2}\right]=4 \times 10^{6} \mathrm{~s}^{-1}$. The decay of free ${ }^{1} \mathrm{O}_{2}$ gives $k_{3}=$ $3.3 \times 10^{4} \mathrm{~s}^{-1}$. The rate constant for the decay of the intermediate, $k_{2}$, is the only parameter fitted in this scheme, because $f_{\Delta}$ (TPP) has been determined, $f_{\Delta}(\mathrm{TPP})=0.92,{ }^{10}$ and $f_{\Delta}(\mathrm{TDFPB})=0.45$ from the singlet-oxygen phosphorescence quantum yields of the aged solution used in this fitting. The singlet-oxygen decays presented in Figure 10 were calculated with $k_{2}=2 \times 10^{6} \mathrm{~s}^{-1}$. This is only an indicative value, reasonable for both TPP and TDFPB. Better fits are achieved with the use of different rates for TPP and TDFPB. For example, using $k_{2}<1 \times 10^{6} \mathrm{~s}^{-1}$ we more closely fit the early peak of the emission sensitized by TDFPB. This is consistent with some degree of charge transfer in the $\left[\mathrm{S} \cdots{ }^{1} \mathrm{O}_{2}\right]$ intermediate, because TDFPB is expected to have a more positive oxidation potential and form a stronger charge-transfer complex with ${ }^{1} \mathrm{O}_{2}$. Such complex will have a lower $k_{\text {sep }}$ and consequently a lower $k_{2}$. A correlation between the rate constant of $\mathrm{T}_{1}$, quenching by $\mathrm{O}_{2}$, and the oxidation potential of the sensitizer was recently reported by Schmidt et al. ${ }^{43}$ for naphthalene derivatives. The remarkable feature of this mechanism is that it shows that half of the singletoxygen molecules sensitized by TDFPB may be deactivated before they separate from the sensitizer.

\section{Conclusion}

5,10,15,20-Tetrakis(2,6-difluorophenyl)bacteriochlorin, 5,10,15,20-tetrakis(2-chlorophenyl)bacteriochlorin and 5,10,15,20tetrakis(2,6-dichlorophenyl)bacteriochlorin are novel bacteriochlorins that can be synthesized by a two-step procedure in high yields, and remain stable at room temperature in solution with or without oxygen for at least 2 weeks. They absorb strongly in the red and give long-lived triplet states with high efficiency. These triplet states transfer their energy very efficiently to singlet oxygen, but nearly half of the sensitized singlet states are quenched before they diffuse into the solution. The halogenated bacteriochlorins are promising, singlet-oxygen sensitizers when irradiation in the red is required.

Acknowledgment. We thank Fundação para a Ciência e Tecnologia for financial support (POCTI/QUI/42536/2001). M.P. received a scholarship from PRAXIS XXI/BD/11398/97. We thank Prof. T. Bernt Melø (Dep. Physics, NUST) for assistance with the singlet-oxygen phosphorescence measurements. L.G.A. wishes to thank the European Science Foundations (ULTRA Program) for a grant.

\section{References and Notes}

(1) Murtinho, D.; Pineiro, M.; Pereira, M. M.; Gonsalves, A. M. d. A. R.; Arnaut, L. G.; Graça Miguel, M.; Burrows, H. D. J. Chem. Soc., Perkin Trans. 2 2000, 2441-2447.

(2) Amor, T. B.; Bortolotto, L.; Jori, G. Photochem. Photobiol. 1998, $68,314-318$.

(3) Brown, J. E.; Brown, S. B. JSDC 1999, 115, 249-253.

(4) Bonnett, R. Chemical Aspects of Photodynamic Therapy; Gordon and Breach Science Publishers: Amsterdam, 2000; Vol. 1.

(5) Smith, K. M.; Pandey, R. K.; Shiau, F.-Y.; Smith, N. W.; Iakovides, P.; Dougherty, T. J. Optical Methods for Tumor Treatment and Detection 1992, 1645, 274-283.

(6) Formosinho, S. J.; Arnaut, L. G.; Fausto, R. Prog. React. Kinetics 1997, 22, 1-90.

(7) Naqvi, K. R.; Steel, C. Spectrosc. Lett. 1993, 26, 1761-1769.

(8) Murtaza, Z.; Graff, D. K.; Zipp, A. P.; Worl, L. A.; Jones, J. W. E.; Bates, W. D.; Meyer, T. J. J. Phys. Chem. 1994, 98, 10504-10513.

(9) Closs, G. L.; Johnson, M. D.; Miller, J. R.; Piotrowiak, P. J. Am. Chem. Soc. 1989, 111, 3751-3753.

(10) Pineiro, M.; Carvalho, A. L.; Pereira, M. M.; Gonsalves, A. M. d. A. R.; Arnaut, L. G.; Formosinho, S. J. Chem. Eur. J. 1998, 4, 22992307.

(11) Pineiro, M.; Pereira, M. M.; Rocha Gonsalves, A. M. d. A.; Arnaut, L. G.; Formosinho, S. J. J. Photochem. Photobiol. A: Chem 2000, 138, $147-157$.

(12) Arnaut, L. G.; Caldwell, R. A.; Elbert, J. E.; Melton, L. A. Rev Sci. Instrum. 1992, 63, 5381-5389.

(13) Seixas de Melo, S.; Silva, L. M.; Arnaut, L. G.; Becker, R. S. J Chem. Phys. 1999, 111, 5427-5433.

(14) Serpa, C.; Arnaut, L. G. J. Phys. Chem. A 2000, 104, 1107511086.

(15) Rocha Gonsalves, A. M. d. A.; Varejão, J. M. T. B.; Pereira, M. M. J. Heterocycl. Chem. 1991, 28, 635-640.

(16) Parker, C. A.; Rees, T. W. Analyst 1960, 85, 587-600.

(17) Huning, S.; Muller, H. R.; Their, W. Angew. Chem., Int. Ed. Engl. 1965, 4, 271-280.

(18) Arnaut, L. G.; Caldwell, R. A. J. Photochem. Photobiol., A 1992, $65,15-20$.

(19) Braslavsky, S. E.; Heibel, G. E. Chem. Rev. 1992, 92, 1381.

(20) Callot, H. J.; Schaeffer, E.; Cromer, R.; Metz, F. Tetrahedron 1990, 46, 5253-5262.

(21) Barloy, L.; Dolphin, D.; Dupré, D.; Wijesekera, T. P. J. Org. Chem. 1994, 59, 7976-7985.

(22) Ito, S.; Murashima, T.; Ono, N. J. Chem. Soc., Perkin Trans. 1 1997, $3161-3165$.

(23) Lash, T. D.; Denny, C. P. Tetrahedron 1995, 51, 59-66.

(24) Faustino, M. A. F.; Neves, M. G. P. M. S.; Vicente, M. G. H.; Cavaleiro, J. A. S.; Neuman, M.; Brauer, H.-D.; Jori, G. Photochem. Photobiol. 1997, 66, 405-412.

(25) Fischer, H.; Eckoldt, H. Liebigs Ann. Chem. 1940, 534, 138-162.

(26) Inhoffen, H. H.; Ullrich, J.; Hoffman, H. A.; Klinzmann, G.; Scheu, R. Liebigs Ann. Chem. 1970, 738, 1-17.

(27) Chang, C. K.; Sotiriou, C. J. Org. Chem. 1985, 50, 4989-4991.

(28) Chang, C. K.; Sotiriou, C. J. Org. Chem. 1987, 52, 926-929. 
(29) Bruckner, C.; Dolphin, D. Tetrahedron Lett. 1995, 36, 3295-3298.

(30) Bonnett, R.; Dimsdale, M. J.; Stephenson, G. F. J. Chem. Soc. C 1969, 564-570

(31) Bonnett, R.; White, R. D.; Winfield, U.-J.; Berenbaum, M. C. Biochem. J. 1989, 261, 277-283.

(32) Inhoffen, H. H.; Buchler, J. W.; Thomas, R. Tetrahedron Lett. 1969, $1141-1144$.

(33) Burns, D. H.; Li, Y. H.; Shi, D. C.; Delaney, M. O. Chem. Commun. 1998, $1677-1678$.

(34) Harel, Y.; Manassen, J. J. Am. Chem. Soc. 1978, 100, 6228-6234.

(35) Scheer, H. Synthesis and Stereochemistry of Hydroporphyrins; Scheer, H., Ed.; Academic Press: New York, 1978; Vol. 2, pp 1-37.

(36) Eisner, U. J. Chem. Soc. 1957, 3461-3469.
(37) Schlesinger, W.; Corwin, A. H.; Sargen, L. J. J. Am. Chem. Soc. 1950, 72, 2867-2871.

(38) Bonnett, R.; Gale, I. A. D.; Stephenson, G. F. J. Chem. Soc. C 1967, 1168-1172.

(39) Whitlock, H. W., Jr.; Hanauer, R.; Oester, M. Y.; Bower, B. K. J. Am. Chem. Soc. 1969, 91, 7485-7489.

(40) Miller, C. E. J. Chem. Educ. 1965, 42, 254-259.

(41) Murphy, S. T.; Kondo, K.; Foote, C. S. J. Am. Chem. Soc. 1999, 121, 3751-3755.

(42) Stauff, J.; Fuhr, H. Z. Naturforsh. 1971, 26B, 260-263.

(43) Schmidt, R.; Shafii, F.; Schweitzer, C.; Abdel-Shafi, A. A.; Wilkinson, F. J. Phys. Chem. A 2001, 105, 1811-1817. 